\title{
Analisa kekuatan mekanik pengaruh perendaman dan penekanan pada komposit berbahan serat mengkuang
}

\author{
Sutrisno ${ }^{1 *}$, Azmal $^{2}$ \\ 1,2Jurusan Teknik Mesin, Politeknik Negeri Pontianak \\ Jl. Ahmad Yani Pontianak \\ ‘Corresponding author: idris_tris@yahoo.com
}

\begin{abstract}
This study aims to determine the effect of mechanical properties, namely the tensile strength, bending and impact of the composite fiber mengkuang (pandanus artocarpus griff) without immersion and with immersion of 5\% $\mathrm{NaOH}$ with an immersion time of 1 hour. Then the blending and casting process is carried out to form a composite material with $20 \%$ fiber and $80 \%$ resin binder with a catalyst content of $1 \%$ and pressurized with press variations of 5 $\mathrm{kg}, 10 \mathrm{~kg}$, and $15 \mathrm{~kg}$. The results of the blending and casting process are made according to the testing standard and then testing the mechanical properties. The results of tensile, bending and impact testing showed that for 1 hour immersion with a pressure of $15 \mathrm{~kg}$ the highest value was tensile strength of $13.75 \mathrm{~N} / \mathrm{mm}^{2}$, bending strength of $33.61 \mathrm{~N} / \mathrm{mm}^{2}$ and impact strength of $152.32 \mathrm{~J} / \mathrm{mm}^{2}$. Whereas the form of the composite fiber of the decomposed fiber is the binder and the fiber breaks evenly at the same point and the fiber is not pulled from the metric.
\end{abstract}

Keywords: composites, resins, mono fiber, mechanical properties

Abstrak

Penelitian ini bertujuan untuk mengetahui pengaruh sifat mekanik yaitu kekuatan tarik, bending dan impact dari komposit serat mengkuang (pandanus artocarpus griff) tanpa perendaman dan dengan perendaman $5 \% \mathrm{NaOH}$ dengan waktu perendaman 1 jam. Kemudian dilakukan proses blending dan casting untuk membentuk menjadi bahan komposit dengan bahan $20 \%$ serat dan $80 \%$ pengikat resin dengan kandungan katalis $1 \%$ serta dilakukan penekanan dengan variasi tekan $5 \mathrm{~kg}, 10 \mathrm{~kg}$, dan $15 \mathrm{~kg}$. Hasil proses blending dan casting dibuat sampel sesuai standar pengujian dan kemudian dilakukan pengujian sifat mekanik. Hasil pengujian kekuatan tarik, bending dan impact didapatkan bahwa pada perendaman 1 jam dengan penekanan $15 \mathrm{~kg}$ dihasilkan nilai tertinggi yaitu kekuatan tarik kekuatan tarik $13,75 \mathrm{~N} / \mathrm{mm}^{2}$, kekuatan bengkok $33,61 \mathrm{~N} / \mathrm{mm}^{2}$, dan kekuatan impact 152,32 J/mm². Sedangkan bentuk dari patahan komposit serat mengkuang yaitu pengikat dan serat putus merata pada satu titik yang sama serta serat tidak tercabut dari metriknya.

Kata kunci: komposit, resin, serat mengkuang, sifat mekanis.

\section{Pendahuluan}

Peningkatan dari aktivis lingkungan dan pelestarian sumber daya alam, serta ketatnya aturan undang-undang yang telah disahkan oleh negara-negara berkembang dengan mengarah ke penemuan dan pengembangan bahan alami dengan fokus pada bahan baku terbarukan [1]. Pada tahun-tahun terakhir ini, berbagai disiplin dan aplikasi mencoba untuk mengganti serat-serat sintetis dengan serat alami sebagai penguat dalam komposit polimer. Karena serat alami biodegradable, murah, ringan dan berlimpah bila dibandingkan dengan serat sintetis [2].

Indonesia adalah negara kaya dengan bahan-bahan serat alam, seperti kapas (cotton), kapuk, goni (jute), sisal, kenaf, pisang kelapa, sawit, rami kasar (flax), rami halus (hemp). Material 
komposit dengan penguatan serat alam (natural fibre) seperti bambu, sisal, hemp, dan pisang telah diaplikasikan pada dunia otomotif sebagai bahan penguat panel pintu, tempat duduk belakang, dashboard, dan perangkat interior lainnya [3].

Dari penelitian-penelitian yang telah dilakukan sebelumnya diketahui bahwa penambahan serat alam akan menambah kekuatan dari komposit. Serat alami diperkuat komposit telah digunakan untuk banyak aplikasi seperti komponen otomotif, bagian dirgantara, barang olahraga, dan industri konstruksi karena sifat menguntungkan dari bahan-bahan ini [4][5].

Penelitian ini dilakukan untuk merancang material komposit baru sebagai pengganti bahan ferrous, nonferrous, atau serat sintetis lainnya untuk sebagai bahan dasar mekanik yaitu sudu turbin, komponen otomotif, atau elemen mesin lainnya. Dengan bahan penguat komposit adalah serat mengkuang, merupakan salah satu tumbuhan sejenis dengan pandan yang tumbuh liar di kawasan lembab dan daerah rawa. Mengkuang juga tumbuh di tepi-tepi sawah dan di tepi sungai. Daun mengkuang berbentuk tirus memanjang dan berduri tajam pada bahagian tepinya, daun mengkuang ini masih belum bermafaat secara optimal.

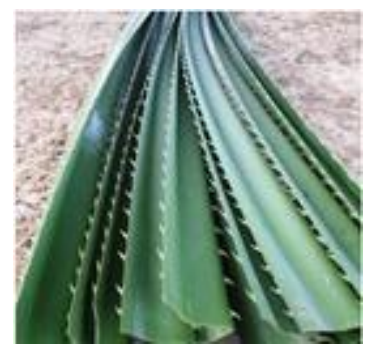

Gambar 1. Daun tumbuhan mangkuang

Penggunaan serat mengkuang sebagai penguat pada material komposit sangat penting dalam rancangan pada material komposit baru untuk dapat menggantikan peranan logam sebagai bahan dasar pembuatan sudu turbin, komponen otomotif atau elemen mesin lainnya.
Produk penelitian ini berupa material komposit berpenguat serat mengkuang sebagai material dasar dalam pembuatan sudu turbin, komponen otomotif atau elemen mesin lainnya. Harapan dari terealisasinya penelitian ini adalah serat mengkuang sebagai salah satu penguat komposit, karena serat mengkuang tanaman banyak yang tumbuh di rawa-rawa dan tepi sungai yang belum dimanfaatkan secara optimal dan hanya menjadi semak belukar.

\section{Metode Penelitian}

Metode yang digunakan adalah metode eksperimen, dimana bahan bakunya menggunakan serat mengkuang sebagai penguat dan matriks mengunakan resin unsaturated polyester 157 BQTN (UPRs) dengan campuran katalis jenis metyl etyl keton perosida (MEKPO). Pembuatan komposit dengan bahan dasar daun mengkuang sebagai serat dan resin sebagai pengikatnya. Serat mengkuang dan resin dibentuk menjadi material berbentuk produk komposit sesuai standar tarik ASTM D 638 - 03, bengkok ASTM D 790 - 02 dan impact ASTM D $256-03$.

Penelitian ini dibuat dengan rendaman $\mathrm{NaOH}$, komposisi campuran serat daun mengkuang dan resin serta diberi tekanan pada proses casting. Pengujian yang akan dilakukan terhadap sampel uji, antara lain uji tarik, uji bending dan uji impact dengan tempat pengujian sampel komposit dilakukan di Laboratorium Pengujian Bahan Jurusan Teknik Mesin Politeknik Negeri Pontianak.

Daun mengkuang yang digunakan adalah daun mengkuang yang sudah tua agar serat yang dihasilkan juga akan lebih baik. Daun mengkuang di-pres dengan alat pengepres dan direndam dengan air tawar selama 24 jam agar mudah untuk memisahkan seratnya. Serat mengkuang diurai menjadi serat dipotong dengan ukuran $170 \mathrm{~mm}$, kemudian serat mengkuang yang masih basah dijemur, setelah kering kemudian direndam dengan $\mathrm{NaOH} 5 \%$ selama 1 jam, selanjutnya di- 
oven dengan suhu $50 \quad{ }^{0} \mathrm{C}$ untuk mempercepat proses pengeringan.

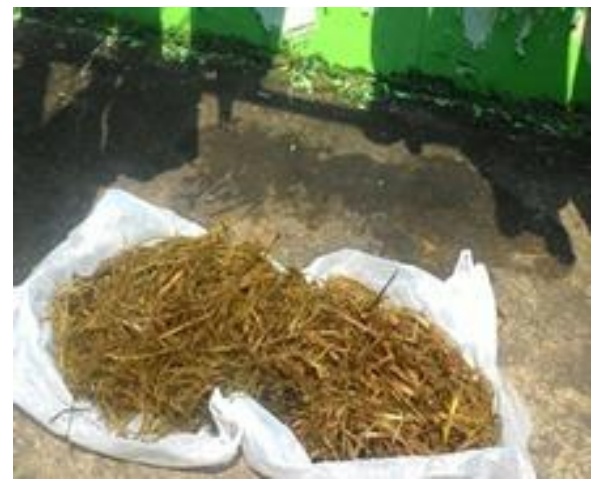

Gambar 2. Serat mangkuang

Untuk pembuatan komposit dilakukan dengan metode hand lay-up dan secara layer by layer dan menggunakan matrik resin unsaturated polyester 157 $B Q T N$ (UPRs) dengan campuran katalis jenis metyl etyl keton perosida (MEKPO). Sedangkan perbandingan antara resin dan katalis adalah setiap $100 \mathrm{cc}$ resin katalis yang digunakan 1 cc dan kemudian dilakukan proses blending dan casting untuk pembentukan komposit dengan $20 \%$ serat $80 \%$ pengikat dan variasi tekanan tekanan $5 \mathrm{~kg}, 10 \mathrm{~kg}$, dan $15 \mathrm{~kg}$. Bentuk produk komposit sesuai standar tarik ASTM D 638 - 03, bending ASTM D 790 - 02 dan impact ASTM D 256 - 03 yang siap untuk dilakukan pengujian [6][7][8].

Pengujian tarik dilakukan untuk mengetahui besarnya kekuatan tarik dari bahan komposit. Pengujian dilakukan dengan mesin uji "Universal Testing Machine”. Spesimen pengujian tarik dibentuk menurut standar ASTM D 638-03 yang ditunjukkan pada gambar 1 sebagai berikut:

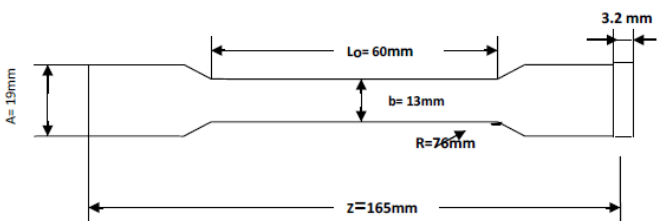

Gambar 3. Dimensi benda pengujian tarik ASTM D $638-03$

Besarnya nilai modulus elastisitas (E) komposit yang juga merupakan perbandingan antara tegangan dan regangan pada daerah proporsional dihitung dengan persamaan:

$$
\mathrm{E}=\sigma_{R} / \varepsilon \quad(\mathrm{MPa})
$$

$\sigma_{t r}$ adalah kekuatan tarik (MPa), dan $\varepsilon$ adalah regangan $(\mathrm{mm} / \mathrm{mm})$.

Pengujian bending produk serat komposit mengikuti standar ASTM D79002 dengan metode three point bengkok (Gambar 4), metode pengujian ini digunakan untuk menentukan kekuatan bengkok terhadap momen bengkok.

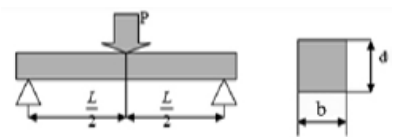

Gambar 4. Penampang uji bengkok [7]

Momen (M) yang terjadi pada komposit dapat dihitung dengan persamaan [7]:

$$
M=\frac{P}{2} \cdot \frac{L}{2} \quad \text { (N.mm) }
$$

Menentukan kekuatan bengkok $\left(\sigma_{b}\right)$ menggunakan persamaan [7]:

$$
\sigma_{b}=\frac{3 . P . L}{2 . b \cdot d^{2}} \quad(\mathrm{MPa})
$$

Sedangkan untuk menentukan modulus elastisitas $\left(E_{b}\right)$ bengkok menggunakan rumus [7]:

$$
E_{b}=\frac{L^{3} \cdot m}{4 \cdot b \cdot d^{3}} \quad(\mathrm{MPa})
$$

$\mathrm{L}$ adalah panjang span $(\mathrm{mm}), \mathrm{P}$ adalah gaya $(\mathrm{N})$, d adalah tebal $(\mathrm{mm}), \mathrm{m}$ adalah hubungan tangensial dari kurva defleksi $(\mathrm{N} / \mathrm{mm})$, dan b adalah lebar ( $\mathrm{mm})$.

Pada penelitian ini untuk mengetahui ketahanan produk komposit terhadap keadaan patah, maka digunakan metode pengujian impact charphy. Dimana batang uji charphy mempunyai luas penampang lintang bujur sangkar (10 x 10) $\mathrm{mm}^{2}$ dengan takikan berbentuk $\mathrm{V}-45^{0}$ dengan kedalaman takik $2 \mathrm{~mm}$.

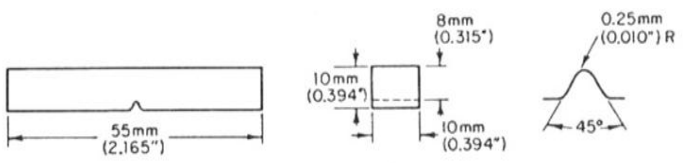

Gambar 5. Dimensi spesimen pengujian impact ASTM D $256-03$

Pada metode pengujian impact charphy sebagaimana ditunjukkan pada gambar 5, produk komposit diletakkan 
mendatar dan kedua ujung produk komposit ditumpu pada suatu landasan. Letak takikan (notch) tepat ditengah dengan arah pemukulan dari belakang takikan. Energi yang dipakai untuk mematahkan produk komposit :

$$
\begin{gathered}
\Delta \mathrm{E}=\left(\mathrm{m} \cdot \mathrm{g} \cdot \mathrm{H}_{1}\right)-\left(\mathrm{m} \cdot \mathrm{g} \cdot \mathrm{H}_{2}\right) \\
\Delta \mathrm{E}=\mathrm{m} \cdot \mathrm{g} \cdot\left(\mathrm{H}_{1}-\mathrm{H}_{2}\right)
\end{gathered}
$$

$\Delta \mathrm{E}$ adalah energi yang diserap (Joule), m adalah berat pendulum $(\mathrm{kg}), \mathrm{g}$ adalah gravitasi bumi $\left(\mathrm{m} / \mathrm{s}^{2}\right), \mathrm{H}_{1}$ adalah posisi awal pemukulan (mm), $\mathrm{H}_{2}$ adalah posisi akhir setelah pemukulan (mm).

Sedang harga kekuatan impak/impact strength $\left(\mathrm{I}_{\mathrm{s}}\right)$ adalah:

$$
\mathrm{I}_{\mathrm{s}}=\Delta \mathrm{E} / \mathrm{A}\left(\mathrm{J} / \mathrm{mm}^{2}\right)
$$

Dengan $\mathrm{A}$ adalah luas penampang efektif produk komposit $\left(\mathrm{mm}^{2}\right)$

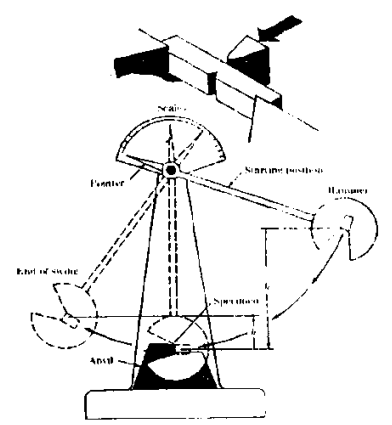

Gambar 6. Alat uji impak

\section{Hasil dan Pembahasan}

Pengujian tarik menggunakan bahan komposit serat mengkuang yang diolah dari proses perendaman dan pengeringan dengan $5 \% \mathrm{NaOH}$ dengan perendaman selama 1 jam, kemudian pembuatan komposit dengan 20\% serat dan $80 \%$ pengikat serta variasi penekanan atau pengepressan dengan beban $5 \mathrm{~kg}, 10 \mathrm{~kg}$ dan 15 kg. Sedangkan Pembuatan dan pengujian komposit (specimen) casting sesuai standar tarik ASTM D 638 - 03.

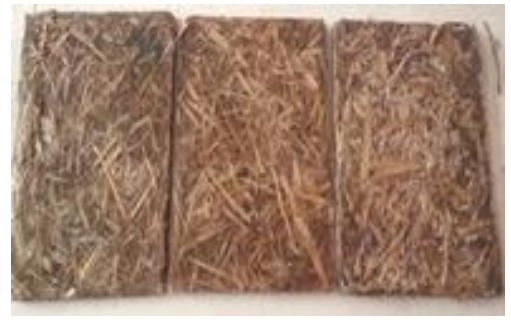

Gambar 7. Komposit serat mengkuang
Pada data pengujian tarik komposit serat mengkuang bahwa dengan perbandingan $20 \%$ serat dan $80 \%$ pengikat tanpa perlakuan perendaman $\mathrm{NaOH}$ dan dengan variasi penekanan bahwa kekuatan tarik paling tinggi pada penekanan $15 \mathrm{~kg}$ yaitu $6,30 \mathrm{~N} / \mathrm{mm}^{2}$. Sedangkan untuk perendaman dengan $\mathrm{NaOH} 5 \%$ dengan waktu 1 jam dan variasi penekanan, kekuatan tarik yang paling besar pada penekanan $15 \mathrm{~kg}$ yaitu $13,75 \mathrm{~N} / \mathrm{mm}^{2}$. Jadi kekuatan tarik tanpa perendaman atau dengan perendaman serta dengan variasi penekanan, kekuatan tarik yang paling besar adalah pada perendaman dengan $\mathrm{NaOH} 5 \%$ dengan waktu 1 jam dan penekanan $15 \mathrm{~kg}$ yaitu $13,75 \mathrm{~N} / \mathrm{mm}^{2}$. Adapun grafiknya dapat dilihat pada Gambar 8.

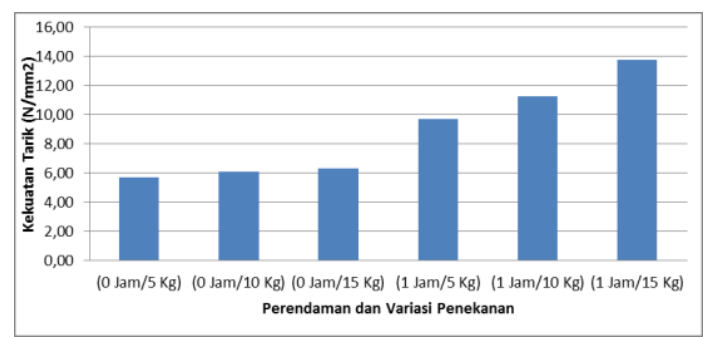

Gambar 8. Grafik hubungan kekuatan tarik dengan perendaman variasi penekanan

Untuk pengujian bengkok menggunakan jenis bahan komposit serat mengkuang yang diolah dari proses perendaman dan pengeringan dengan $5 \%$ $\mathrm{NaOH}$ dan perendaman selama 1 jam, kemudian pembuatan komposit dengan $20 \%$ serat dan $80 \%$ pengikat serta variasi penekanan atau pengepressan dengan beban $5 \mathrm{~kg}, 10 \mathrm{~kg}$ dan $15 \mathrm{~kg}$. Pembuatan dan pengujian komposit (specimen) casting sesuai standar bending ASTM D 790 - 02. Pada pengujian bengkok untuk komposit serat mengkuang dengan perbandingan $20 \%$ serat dan $80 \%$ pengikat tanpa perlakuan perendaman $\mathrm{NaOH}$ dan dengan variasi penekanan bahwa untuk penekanan $15 \mathrm{~kg}$ kekuatan bengkok paling tinggi yaitu 25,12 N/mm ${ }^{2}$. Sedangkan dengan perendaman dengan $\mathrm{NaOH} 5 \%$ dengan waktu 1 jam dan variasi penekanan, kekuatan bengkok yang paling besar pada 
penekanan $15 \mathrm{~kg}$ yaitu 33,61 N/mm². Jadi kekuatan bengkok tanpa atau dengan perendaman serta dengan variasi penekanan kekuatan bengkok yang paling besar pada perendaman $\mathrm{NaOH} 5 \%$ dengan waktu 1 jam dan penekanan $15 \mathrm{~kg}$ yaitu 33,61 $\mathrm{N} / \mathrm{mm}^{2}$. Adapun grafiknya dapat dilihat pada Gambar 9.

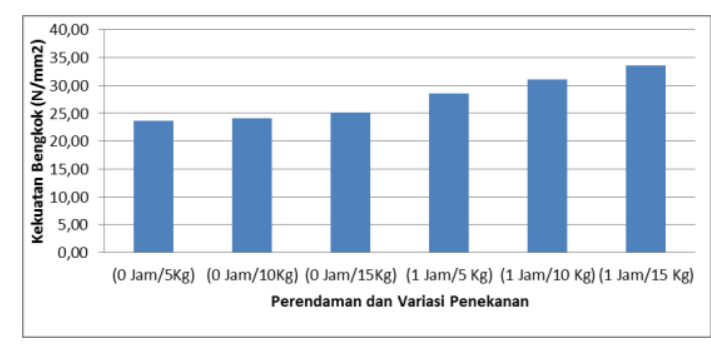

Gambar 9. Grafik hubungan kekuatan bengkok dengan perendaman dan variasi penekanan

Untuk pengujian impact menggunakan jenis bahan komposit serat mengkuang yang diolah dari proses perendaman dan pengeringan dengan $5 \%$ $\mathrm{NaOH}$ dan perendaman selama 1 jam, kemudian pembuatan komposit dengan $20 \%$ serat dan $80 \%$ pengikat serta variasi penekanan atau pengepresan dengan beban $5 \mathrm{~kg}, 10 \mathrm{~kg}$, dan $15 \mathrm{~kg}$. Sedangkan pembuatan dan pengujian komposit (specimen) casting sesuai standar impact ASTM D 256 - 03. Pengujian impact untuk komposit serat mengkuang dengan perbandingan $20 \%$ serat dan $80 \%$ pengikat tanpa perlakuan perendaman $\mathrm{NaOH}$ dan variasi penekanan adalah pada penekanan $15 \mathrm{~kg}$ dengan kekuatan impact paling tinggi $137,47 \mathrm{~J} / \mathrm{mm}^{2}$. Sedangkan untuk perendaman $\mathrm{NaOH} 5 \%$ dengan waktu 1 jam dan variasi penekanan, kekuatan impact yang paling besar pada penekanan $15 \mathrm{~kg}$ yaitu $152,32 \mathrm{~J} / \mathrm{mm}^{2}$. Jadi kekuatan impact tanpa atau dengan perendaman 1 jam serta dengan variasi penekanan, kekuatan impact yang paling besar pada perendaman $\mathrm{NaOH} 5 \%$ dengan waktu 1 jam dan penekatan $15 \mathrm{~kg}$ yaitu 152,32 $\mathrm{J} / \mathrm{mm}^{2}$. Adapun grafiknya dapat dilihat pada gambar 3 .

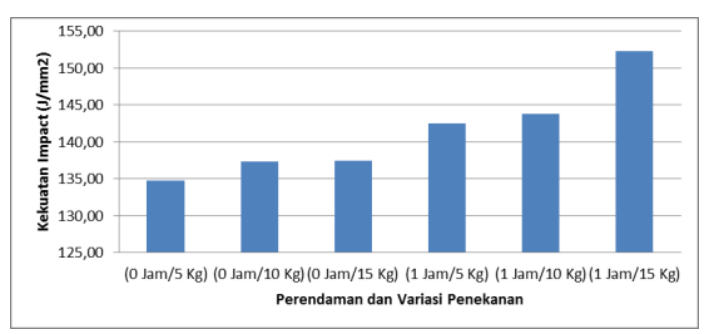

Gambar 3. Grafik hubungan kekuatan impact dengan perendaman variasi penekanan

Berdasarkan data-data di atas menunjukkan bahwa hasil pengujian kekuatan tarik, kekuatan bengkok dan kekuatan impact ada peningkatan kekuatan dengan meningkatnya penekanan yang dilakukan pada proses pembuatan komposit (specimen) casting, sehingga serat dan pengikat dapat mengikat dengan membentuk mikrostruktur yang padat. Ini dapat dilihat dari bentuk patahan dari tiga hasil pengujian tarik, bengkok, dan impact yaitu pengikat dan serat putus merata pada satu titik yang sama serta serat tidak tercabut dari metriknya. Selain ini juga proses perendaman serat mengkuang juga mempengaruhi kekuatan dari serat dimana perendaman dengan $\mathrm{NaOH} \mathrm{5 \%} \mathrm{tidak} \mathrm{boleh}$ lebih atau kurang dari 1 jam, dan juga penyebaran serat dalam proses pembuatan komposit (specimen) casting juga sangat mempengaruhi terhadap kekuatan dari bahan komposit.

\section{Kesimpulan}

Kekuatan tarik, bengkok, dan impact yang tertinggi dihasilkan dari komposit serat mengkuang pada perendaman $\mathrm{NaOH} 5 \%$ dengan waktu perendaman 1 jam dan variasi penekanan $15 \mathrm{~kg}$, yaitu untuk kekuatan tarik 13,75 $\mathrm{N} / \mathrm{mm}^{2}$, kekuatan bengkok $33,61 \mathrm{~N} / \mathrm{mm}^{2}$ dan kekuatan impact $152,32 \mathrm{~J} / \mathrm{mm}^{2}$.

Bentuk patahan dari hasil pengujian tarik, bending, dan impact komposit serat mengkuang yaitu pengikat dan serat putus merata pada satu titik yang sama serta serat tidak tercabut dari metriknya. Metode dan proses yang dilakukan pada komposit serat mengkuang ini dapat juga dilakukan untuk 
komposit lain sehingga didapatkan kekuatan bahan yang diinginkan.

\section{Ucapan Terimakasih}

Ucapan terimakasih disampaikan kepada pimpinan Politeknik Negeri Pontianak dan Struktural Jurusan Teknik Mesin yang telah membantu dalam pendanaan dan proses penelitian yang dilakukan hingga penulisan dalam Jurnal Turbo ini. Dan tak lupa juga ucapan terima kasih kepada rekan sejawat dan mahasiswa Jurusan Teknik Mesin serta pengurus Jurnal Turbo yang telah membantu dalam proses penulisan hingga diterbitkan penulisan ini.

\section{Referensi}

[1] M. Jawaid, H.P.S. Abdul Khalil (2011), Cellulosic/synthetic fibre reinforced polymer hybrid composites: A review. Carbohydrate Polymers, 86(1), 1-18.

[2] D.N. Saheb, J.P. Jog, (1999), Natural fibre polymer composites: a review. Advances in polymer technology, 18(4), 351-363.

[3] Boeman, R. G., and Johnson, N. L., (2002), Development of a Cost Competitive, Composite Intensive, Body-in-white, Journal SAE, No. 200201-1905.

[4] Rozman, H.D., Kon, B.K., Abusamah, A., Kumar, R.N., Mohd. Ishak, Z.A. (1998), Rubberwood-High-Density Polyethylene Composites: Effect of Filler Size and Coupling Agents on Mechanical Properties, Journal of Applied Polymer Science, Volume 69, Issue 10, halaman: 1993-2004.

[5] Nurudin, A. (2011), Potensi Pengembangan Komposit Berpenguat Serat Kulit Waru (Hibiscus Tiliaceus) Kontinyu Laminat Sebagai Material Pengganti Fiberglass Pada Pembuatan Lambung Kapal, Info Teknik, Volume 12 No. 2.

[6] ASTM D 256, 2003, Standard test methode for determining charpy impact strength of plastic. American Society for Testing Materials, Philadelphi4 PA.

[7] ASTM. D 790 - 02, Standard test methods for flexural properties of unreinforced and reinforced plastics and electrical insulating material. Philadelphia, PA: American Society for Testing and Materials.

[8] ASTM International, 2002, The Composite Materials Handbook, Polymers Matrix Composite, volume 3. Baltimore, USA. 